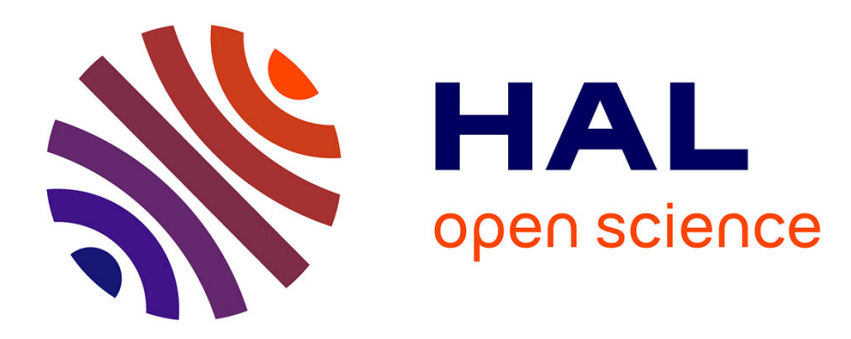

\title{
Validation of the predation-stress hypothesis in a large mammal
}

\author{
Benjamin Rey
}

\section{To cite this version:}

Benjamin Rey. Validation of the predation-stress hypothesis in a large mammal. Functional Ecology, 2020. hal-02566914

\section{HAL Id: hal-02566914 \\ https://cnrs.hal.science/hal-02566914}

Submitted on 7 May 2020

HAL is a multi-disciplinary open access archive for the deposit and dissemination of scientific research documents, whether they are published or not. The documents may come from teaching and research institutions in France or abroad, or from public or private research centers.
L'archive ouverte pluridisciplinaire HAL, est destinée au dépôt et à la diffusion de documents scientifiques de niveau recherche, publiés ou non, émanant des établissements d'enseignement et de recherche français ou étrangers, des laboratoires publics ou privés. 


\title{
Validation of the predation-stress hypothesis in a large mammal
}

\author{
Benjamin Rey ${ }^{1,2}$ (D) \\ ${ }^{1}$ Laboratoire de Biométrie et Biologie Evolutive, Université de Lyon, Université Lyon 1, CNRS, UMR5558, Villeurbanne, France \\ ${ }^{2}$ Brain Function Research Group, School of Physiology, Faculty of Health Sciences, University of the Witwatersrand, Johannesburg, South Africa
}

Correspondence: Benjamin Rey

Email: benjamin.rey@univ-lyon1.fr

Seventy years after the discovery that steroid metabolites measured in urine or faeces reflect circulating hormone levels, non-invasive measurements of glucocorticoids and their derivative from various biological matrices have become one of the most essential tools in the functional ecologist's repertoire (Palme, 2019; Sheriff, Dantzer, Delehanty, Palme, \& Boonstra, 2011). Glucocorticoids (cortisol and corticosterone) are vertebrate metabolic hormones involved in energy maintenance and regulation whose secretion increases drastically in response to various physiological and psychological stressors. Although the release of glucocorticoids in response to a stressor aimed at maintaining or restoring homoeostasis and provides direct fitness benefits in the short-term, chronically elevated glucocorticoid levels can affect key body functions such as immunity, growth or reproduction, even if the intensity of these effects seems to vary from one species to another (Boonstra, 2013).

Given the duality of glucocorticoid effects on animal performance parameters, describing the patterns of glucocorticoids in natural populations became a major element for characterizing the role of stress as an ecological driving force and a key player in evolution. In this context, the vast majority of studies found in the literature aim at determining the environmental (extrinsic) and individual (intrinsic) drivers of glucocorticoids levels. In contrast, very few studies have sought to establish causal relationships between level of glucocorticoids, animal performance, fitness and how these translate into population dynamics (Beehner \& Bergman, 2017; Breuner, Patterson, \& Hahn, 2008).

Functional links between the causes and consequences of stress on demography were established in an elegant study by Dulude-de Broin and his collaborators in the current issue of Functional Ecology (Dulude-de Broin, Hamel, Mastromonaco, \& Côté, 2020). Using the mountain goat Oreamnos americanus of the Canadian Rockies as study model, the authors validated for the first time in a wild population of large mammals the 'predation-stress hypothesis' which predict that repeated exposure to predators would affect the fitness components and demographic trajectories of their prey through deleterious effects of chronic stress. To achieve their goal, the authors have combined an impressive array of environmental, physiological and demographic data on mountain goats collected over 23 years in a multi-predator system, raising the bar high in the field of stress ecology. Exposure to predators, quantified as the probability of encountering one of the predator species at the study site, was determined by intense monitoring in the field and was used as an explanatory variable to model patterns of glucocorticoids levels. Other environmental factors, such as the availability of resources (measured as faecal crude protein peak) and population size, were also quantified each year and taken into account in the analyses. Faeces and hair samples were collected each summer during captures and were used to model annual estimates of glucocorticoid levels in the population while controlling for potential individual effects such as age, sex and body mass and seasonal variations. To link the effects of fluctuating glucocorticoids to population dynamics, the authors quantified reproductive success as the proportion of reproductive females each year in the population. Finally, the causal relationship between the risk of predation, the levels of glucocorticoids at the population level and the reproductive success were established by performing path analyses.

The results are unequivocal: increasing the risk of encountering predators (grizzly and black bears, wolves, cougars, coyotes and wolverines) had a direct positive effect on faecal glucocorticoids metabolites (FGM) which, in turn, negatively affected the proportion of reproductive females in the population. In short, a 30\% drop in the proportion of reproductive females was observed in the years when the level of FGM is high compared to the years when the level of FGM is low, with a resounding effect on demography. Although the data do not allow determining whether the stress-induced increase in glucocorticoids primarily affects female or male fertility-and this constitutes the next challenge for future studies-the current finding supports the idea that the physiological anti-predator responses 
bear energy costs that impact reproduction with measurable impact on demography.

These findings are of great value to community ecology as they identify, for the first time in a large mammal, a physiological mechanism by which predator-prey interactions other than predation may shape communities. In many taxa, the impact of those interactions (also referred as non-consumptive effects of predation) on the demography of their prey are predominant and even greater than the direct effect of predation (Preisser, Bolnick, \& Benard, 2005). In large mammals, the non-consumptive effects of predation are classically attributed to behavioural anti-predator responses such as habitat shift or temporal avoidance (Say-Sallaz, Chamaillé-Jammes, Fritz, \& Valeix, 2019). By establishing causal relationships between predation risk, glucocorticoids levels and reproductive outputs, the findings of Dulude-de Broin et al. (2020) on mountain goats provide an alternative scenario to that proposed for other ungulates for which the predation stress hypothesis is typically not valid (e.g. Creel, Winnie, \& Christianson, 2009). Hence, Dulude-de Broin's observations suggest that the nature of the anti-predatory response and the associated cost depend on the ecological context. The predation-stress hypothesis would apply when the presence of predators cannot be predicted and/or proactively mitigated by behavioural responses, and these conditions are met in the case of mountain goats (Dulude-de Broin et al., 2020).

Although quantifying the effect of the risk of predation on the reproduction and survival of prey in wild populations of large mammals poses serious challenges (Say-Sallaz et al., 2019), the article by Dulude-de Broin highlights the importance of considering both physiological and behavioural responses to predation risks for a better understanding of the dynamics of predator-prey interactions. To this end, extrapolating the stress response from proxies of glucocorticoids levels appear to be relevant to link the physiology to fitness components even if there are limitations. In particular, the large unexplained residual variability that emerges from the models, including when many confounding factors are taken into account (Dulude-de Broin et al., 2020), suggest that glucocorticoids levels may include multiple components, potentially other than stress, that obscure the signal. In the current context where science is bogged down in a replication crisis (Baker, 2016) which does not spare the field of ecology and evolution (Fraser, Parker, Nakagawa, Barnett, \& Fidler, 2018), using several complementary approaches to quantify the response stress-as was done in Dulude-de Broin's study and in other recent studies in stress ecology (e.g. Boudreau et al., 2019)-may soon become a methodological requirement. On a larger scale, there is a need to focus on other physiological aspects such as the metabolic (energy) and somatic costs (e.g. oxidative stress, immune function) associated with the risk of predation in large mammals. This 'strategic use of multiple approaches to answer a question' qualified as 'triangulation' by Munafò and Smith (2018) is necessary for a global understanding of the physiological cost of predation risk and their cascading effects on prey population dynamics.

\section{ORCID}

Benjamin Rey iD https://orcid.org/0000-0002-0464-5573

\section{REFERENCES}

Baker, M. (2016). Reproducibility crisis? Nature, 533, 353-366.

Beehner, J. C., \& Bergman, T. J. (2017). The next step for stress research in primates: To identify relationships between glucocorticoid secretion and fitness. Hormones and Behavior, 91, 68-83. https://doi. org/10.1016/j.yhbeh.2017.03.003

Boonstra, R. (2013). Reality as the leading cause of stress: Rethinking the impact of chronic stress in nature. Functional Ecology, 27, 11-23. https://doi.org/10.1111/1365-2435.12008

Boudreau, M. R., Seguin, J. L., Boonstra, R., Palme, R., Boutin, S., Krebs, C. J., \& Murray, D. L. (2019). Experimental increase in predation risk causes a cascading stress response in free-ranging snowshoe hares. Oecologia, 191, 311-323. https://doi.org/10.1007/s00442019-04500-2

Breuner, C. W., Patterson, S. H., \& Hahn, T. P. (2008). In search of relationships between the acute adrenocortical response and fitness. General and Comparative Endocrinology, 157, 288-295. https://doi. org/10.1016/j.ygcen.2008.05.017

Creel, S., Winnie, J. A., \& Christianson, D. (2009). Glucocorticoid stress hormones and the effect of predation risk on elk reproduction. Proceedings of the National Academy of Sciences of the United States of America, 106, 12388-12393. https://doi.org/10.1073/pnas.09022 35106

Dulude-de Broin, F., Hamel, S., Mastromonaco, G. F., \& Côté, S. D. (2020). Predation risk and mountain goat reproduction: Evidence for stress-induced breeding suppression in a wild ungulate. Functional Ecology, 34, 1003-1014. https://doi.org/10.1111/1365-2435.13514

Fraser, H., Parker, T., Nakagawa, S., Barnett, A., \& Fidler, F. (2018). Questionable research practices in ecology and evolution. PLoS ONE, 13(7), e0200303. https://doi.org/10.1371/journal.pone.0200303

Munafò, M. R., \& Smith, G. D. (2018). Robust research needs many lines of evidence. Nature, 399-401. https://doi.org/10.1038/d4158 6-018-01023-3

Palme, R. (2019). Non-invasive measurement of glucocorticoids: Advances and problems. Physiology and Behavior, 199, 229-243. https://doi.org/10.1016/j.physbeh.2018.11.021

Preisser, E. L., Bolnick, D. I., \& Benard, M. F. (2005). Scared to death? The effects of intimidation and consumption in predator-prey interactions. Ecology, 86, 501-509. https://doi.org/10.1890/04-0719

Say-Sallaz, E., Chamaillé-Jammes, S., Fritz, H., \& Valeix, M. (2019). Non-consumptive effects of predation in large terrestrial mammals: Mapping our knowledge and revealing the tip of the iceberg. Biological Conservation, 235, 36-52. https://doi.org/10.1016/j.biocon. 2019.03.044

Sheriff, M. J., Dantzer, B., Delehanty, B., Palme, R., \& Boonstra, R. (2011). Measuring stress in wildlife: Techniques for quantifying glucocorticoids. Oecologia, 166, 869-887. https://doi.org/10.1007/ s00442-011-1943-y 